\title{
System Justification and the Defense of Committed Relationship Ideology
}

\author{
Martin V. Day \\ University of Waterloo \\ John G. Holmes \\ University of Waterloo
}

\author{
Aaron C. Kay \\ Duke University \\ Jaime L. Napier \\ Yale University
}

\begin{abstract}
A consequential ideology in Western society is the uncontested belief that a committed relationship is the most important adult relationship and that almost all people want to marry or seriously couple (DePaulo $\&$ Morris, 2005). In the present article, we investigated the extent to which the system justification motive may contribute to the adoption of this ideology. In Studies 1 and 2, we examined whether a heightened motive to maintain the status quo would increase defense of committed relationship values. In Study 3, we examined the reverse association, that is, whether a threat to committed relationship ideology would also affect sociopolitical system endorsement. As past research has found that the justification of political systems depends upon how much these systems are perceived as controlling, in Study 4 we tested whether the defense of the system of committed relationships would also increase when framed as controlling. Results from Studies 1-4 were consistent with our hypotheses, but only for men. In Study 5 , using cross-cultural data, we sought to replicate these findings correlationally and probe for a cause of the gender effect. Results from more than 33,000 respondents indicated a relationship (for men) between defense of the sociopolitical system and defense of marriage in countries where the traditional advantages of men over women were most threatened. In Studies 6 and 7, we investigated when this gender difference disappears. Results revealed that when we measured (Study 6) or manipulated (Study 7) personal relationship identity rather than relationship ideology, effects also emerge for women.
\end{abstract}

Keywords: ideology, system justification, gender, relationships, identity

"We could be married, and then we'd be happy." -Brian Wilson, The Beach Boys

As reflected in the quotation above, marriage - or the official act of long-term partnership - is often assumed to provide unique benefits to people's lives, imbuing them with clarity, guidance, happiness, fulfillment, and meaning. DePaulo and Morris (2005) have recently noted this uncontested, and even vociferously defended, set of beliefs, which we refer to here as committed relationship ideology. This ideology comprises all heterosexual rela-

This article was published Online First April 11, 2011

Martin V. Day and John G. Holmes, Department of Psychology, University of Waterloo, Waterloo, Ontario, Canada; Aaron C. Kay, Department of Management, Fuqua School of Business, and Department of Psychology and Neuroscience, Duke University; Jaime L. Napier, Department of Psychology, Yale University.

This research was funded by Social Sciences and Humanities Research Council of Canada grants to Aaron C. Kay and John G. Holmes. Portions of this research were presented at conferences for the International Society for Justice Research (Banff, Alberta, Canada; August, 2010), the Society for Personality and Social Psychology (Las Vegas, Nevada; January, 2010), and the Canadian Psychological Association (Halifax, Nova Scotia, Canada; June, 2008). We thank Michael Ross, Steve Spencer, Gráinne Fitzsimons, and Pauline Loucks for their contributions to this project.

Correspondence concerning this article should be addressed to Martin V. Day, Department of Psychology, University of Waterloo, 200 University Avenue West, Waterloo, Ontario, Canada, N2L 3G1. E-mail: mvday@uwaterloo.ca tionships that are enduring, dependable, and romantic in nature. It includes the assumptions that most people wish to get married and that the committed relationship is the most important relationship, above friendships or other adult relationships. Committed relationships are valued so much that those who attain this status are in many ways considered to be better than those who remain single (DePaulo \& Morris, 2005).

This contrast with singles has its costs. Whereas people in committed relationships are often perceived favorably, people who are single are negatively stereotyped as less mature, more lonely, less secure, and more likely to be unhappy (Morris, DePaulo, Hertel, \& Taylor, 2008). Although researchers have found little actual support for the veracity of these stereotypes (Greitemeyer, 2009), they appear to be widely accepted, applied to male and female singles who are as young as 25 years old (Morris et al., 2008) and even to singles who demonstrate social skills by maintaining close friendships (Conley \& Collins, 2002). Labeled singlism (DePaulo \& Morris, 2005, 2006), this longstanding practice of discrimination against singles is still legal in most settings and is only slowly being recognized by the public and media. Interestingly, explicit discrimination and stereotyping of singles has been endorsed not only by people in relationships but also by people who are single (Morris et al., 2008).

To many, it is puzzling as to why people commonly hold such strong beliefs about the inherent "goodness" of committed relationships and react so negatively to those that challenge them. But there has been relatively little psychological analysis or discussion of this specific ideology, especially when compared to other ide- 
ological beliefs, such as political orientation. Why are relationships, and, more specifically, the institution of marriage, so broadly defended? Although there are likely a variety of reasons why this motivated belief persists, few, if any, empirical studies have been devoted to understanding the underlying factors. In this article, we propose that the endorsement and defense of committed relationship ideology may help satisfy epistemic and existential needs that have previously been associated with motivations to believe in a fair and just society (Jost \& Banaji, 1994).

System justification theory (Jost \& Banaji, 1994; Jost, Banaji, \& Nosek, 2004) posits that people are motivated to perceive current social, economic, and political arrangements as orderly, fair, just, and legitimate. One of the primary drivers behind the system justification motive is the motivation to shield one's self from the existential and epistemic threats that would surface if uncertain, illegitimate, or disorderly system conditions were acknowledged (Jost \& Hunyady, 2005; Kay, Gaucher, Napier, Callan, \& Laurin, 2008). In other words, believing that sociopolitical systems and prevailing hierarchies are just, legitimate, and orderly can protect people from the threat associated with randomness, uncertainty, and injustice. Thus, to the extent that the system of committed relationships is associated with the overarching societal system, it is conceivable that endorsing this ideology may serve the same needs as endorsing other aspects of the system. That is, committed relationship ideology may be explained, at least in part, by the system justification motive.

\section{Committed Relationship Ideology and Motivations to Maintain the Status Quo}

DePaulo and Morris (2005) have outlined several possible explanations for the origins of committed relationship ideology. For example, from an evolutionary perspective, they noted that desiring a romantic partner, having sex, and producing offspring are adaptive for the survival of the species and may partly explain why committed relationships are more valued than being single (Pillsworth \& Haselton, 2005). Other accounts suggest this ideology originated from its utility in facilitating social control or creating economic value (see DePaulo \& Morris, 2005, including commentaries and response). But regardless of how these beliefs originated, one clear contributor to their maintenance, according to DePaulo and Morris, is that society does not challenge them. Rather, most members of society endorse these beliefs, either explicitly via stated opinions or implicitly via the failure to state otherwise (Miller \& Ratner, 1998).

The prototypical example of a committed relationship is marriage, a longstanding cultural tradition. Unlike some other traditions and rituals, however, marriage has become an institution that confers legitimacy. People become legally married. This implies not only that society accepts this form of relationship, but it also conveys that larger governing systems have power over this relationship. Marriage is therefore entrenched in the status quo not only as a tradition but also as a part of a larger governmental framework that reinforces social norms. Given people's tendency to defend the status quo and social norms (Jost \& Banaji, 1994; Kay et al., 2009), the institution of committed relationship ideology may benefit from its association with the broader governmental system.
Moreover, much like other phenomena related to system justification, endorsing committed relationship ideology may help people preserve beliefs in control and order, as opposed to randomness and uncertainty (Kay et al., 2008). As recent research has demonstrated, sociocultural systems that offer a sense of order to the individual are much more likely to become legitimized and defended as important components of the status quo (Kay et al., 2008, 2009). The belief that most people should join committed relationships may help alleviate feelings of an uncertain future, replacing it with a more predictable path and a clear set of life guides. There are also often rules associated with committed relationships (e.g., roles, division of labor, courting procedures) that may reduce feelings of disorder. Finally, beliefs about committed relationships may also bolster expectancies of security and stability, especially compared with perceptions of single life. It is possible, therefore, that as with other elements of the status quo, endorsement of the institution of marriage may help satiate broad needs to believe in an orderly and predictable system.

Recent research on system justification theory has explored the substitutable, hydraulic nature of people's endorsement of seemingly unrelated external systems (such as governments, religions, organizations, etc.). This research has demonstrated that external systems that confer order and control to one's social world can be flexibly relied upon to maintain these cherished beliefs (Kay et al., 2008; Kay, Shepherd, Blatz, Chua, \& Galinsky, 2010). Thus, if beliefs about committed relationships are intertwined with beliefs about other legitimized institutions (e.g., the government, religion) that also confer order to people's lives, then the endorsement of committed relationship ideology should demonstrate a substitutable relation with other aspects of the sociopolitical system that have traditionally been associated with satiating system justification needs. Threats to these other aspects of the system (such as the government) should cause heightened support for committed relationship ideology, and threats to committed relationship ideals (e.g., exposure to high divorce rates, attempts to alter the definition of marriage) should cause heightened support for these other systems. In addition, if committed relationship ideology does help people cope with needs for order and certainty in the same way that other aspects of the sociopolitical system have been shown to do, then any manipulation that increases perceptions that relationships provide these specific benefits should increase endorsement of this ideology.

Although there has been much theorizing and investigation into the development of committed relationships (e.g., Kelley, 1983; Murray, Holmes, \& Collins, 2006), there have been no experimental investigations of the factors that influence the support of committed relationship ideology. Given the serious consequences of this ideology - including the derogation of singles and fears of changing the "rules" so as to include same-sex marriage-further research attention is warranted. To this end, we employ converging experimental and correlational methodologies to examine whether relationship ideology defense can be explained, at least in part, by the general motive to defend one's overarching sociopolitical system.

\section{Gender Differences}

Given that men and women tend to differ in many important ways with regards to how they think about and identify with 
traditional romantic relationships, there is reason to believe that the contexts that predict relationship beliefs may differ for men and women. Close relationships tend to be more associated with women's identities than men's (Cross \& Madson, 1997). As an example, relational self-construal scores suggest that women view their close relationships as more fundamental to the self and as a more intrinsic part of their self-concepts than do men (Cross, Bacon, \& Morris, 2000; Guimond, Chatard, Martinot, Crisp, \& Redersdorff, 2006). Provided that women are inclined to think about and identify with close relationships more than men, it is possible, therefore, that women may also be more likely to rely on their own close relationships and general beliefs about relationships when faced with external threat. On the other hand, it is also feasible that men's defense of committed relationship ideology may be more responsive to threat-especially system threat. This is because the social and economic advantages of the overall system are believed to be severely skewed toward men (e.g., see Jackman, 1994; Sidanius \& Pratto, 1999), an asymmetry thought to be maintained in large part by traditional social roles, stereotypes, values, and norms of male-female dynamics (e.g., Deaux, 1985; Eagly, 1987; Glick \& Fiske, 1996, 2001; Jackman, 1994; Jost \& Kay, 2005; Pratto \& Walker, 2004; Rudman \& Glick, 1999). Consistent with this account, data from several different cultures suggest that men, compared with women, show greater overall support for traditional social structures and hierarchies and less support for equality (Sidanius, Levin, Liu, \& Pratto, 2000; Sidanius, Pratto, \& Bobo, 1994). It is also possible, therefore, that men may act more defensively than women when the traditional system of gender relations is challenged.

Thus, although we are not offering any straightforward gender-based predictions, it is clear that men and women derive unique benefits from relationships. Men may derive more power from the traditional system of relationships, but women integrate individual relationships more deeply into their sense of self. As such, it is conceivable that men and women may differ in the extent to which they defend traditional relationship ideology when it, or the broader system it is intertwined with, comes under attack.

\section{Study 1}

Our objective in the first study was to test whether activating the system justification motive would increase defense of committed relationship ideology. Participants were first exposed to a manipulation of either low or high system threat, to vary the strength of the system justification motive. Just as depriving one of food or drink makes someone hungrier or thirstier, and threatening one's self or group identity has been shown to engage self or group protective motives (e.g., Fein \& Spencer, 1997; Sherman \& Cohen, 2002; Steele \& Liu, 1983), threatening the sociopolitical system through broad challenges to system legitimacy has been shown to activate the system justification motive (Hafer, 2000; Jost, Kivetz, Rubini, Guermandi, \& Mosso, 2005; Kay, Jost, \& Young, 2005). Following exposure to system threat, participants were asked to evaluate research findings that either supported or did not support the common content of relationship ideology. We hypothesized that after exposure to high (but not low) system threat, participants would be more critical of research that does not support relationship ideology compared with research that does. We did not expect participants to be more critical of everything following high system threat, or more critical whenever relationship ideology is not supported. Rather, we expected criticisms of research to increase only following high system threat and only when the research findings do not support relationship ideology.

\section{Method}

Participants. Ninety-eight participants (54 women, 42 men, two undisclosed; $M=21.37$ years) were recruited from the University of Waterloo campus and participated in exchange for a chocolate bar. ${ }^{1}$ Forty-nine were involved in romantic relationships averaging 23.71 months in length $(S D=16.52), 47$ identified as being single, and two did not list their relationship status. Larger ethnic groups included $67.3 \%$ White, $19.4 \%$ Asian, and 3.1\% East Indian.

Procedure. Participants volunteered for a study on "publicly relevant media and research," under the guise that the study aimed to better understand public opinions on this topic. An experimenter, who was blind to condition, handed all participants a booklet and asked them to follow the directions carefully and complete the materials on their own.

Manipulation of system threat. Participants were first instructed to read one of two possible magazine articles about the lives of Arab Canadians. These articles were chosen because they have been demonstrated in past research to threaten the legitimacy of the existing sociopolitical system (Day, Yoshida, \& Kay, 2011; adapted from Hahn \& Cohen, 2008). Prior research has found that similar system threats activate the system justification motive but do not affect levels of individual or collective self-esteem (Kay et al., 2005). This particular article either depicted systematic, unfair discrimination against Arab Canadians (high system threat) or suggested that Arab Canadians were not targets of discrimination (low system threat).

Manipulation of committed relationship ideology support. Next, participants were asked to read and provide their opinions on a research report, which was designed to support or not support ideal beliefs about committed relationships. The research report contained details about a study, including the research goal, method, and conclusions, based on a previously developed paradigm (Lord, Ross, \& Lepper, 1979; Pomerantz, Chaiken, \& Tordesillas, 1995). Participants read that the aim of the study was to investigate the life benefits of being in a long-term relationship. The study descriptions were identical for all participants with the exception of the research conclusions. Participants in the relationship ideology supported condition read the following research conclusions:

The researchers found a link between being in a committed romantic relationship and overall life benefits, compared to singles,

\footnotetext{
${ }^{1}$ Three additional Arab Canadian participants (all male) were not included in the final sample due to the specific manipulation of system threat used, which involved descriptions of discrimination against Arab Canadians. Leaving these participants in, however, did not change the pattern of results and or the significance of the main findings.
} 
for people in their mid-thirties. The researchers found support in this study that suggests long-term relationships are beneficial to people's well-being. Overall, mid-life adults in relationships are better off than mid-life adults who are single. Specifically, couples reported feeling more secure and stable in their life than single people reported. People in long-term relationships felt they could rely and depend on their partners more than single people could rely on others. In addition, when couples were asked to list personal benefits of being in a relationship they generated more benefits than when single people were asked to list the benefits of being single. Interestingly, couples also felt they were meeting their life goals more than singles, and felt their lives to have improved more than single people reported. Further, in terms of life satisfaction and happiness, people in committed relationships reported being happier than single people. These findings were consistent at Time 1 and at Time 2 (after one year).

Participants in the relationship ideology not supported condition read a similarly worded paragraph about the research but that concluded that there was no link between being in a committed romantic relationship and overall life benefits compared with being single. Participants read that people in relationships did not feel more secure or stable and did not depend on others more than did singles. People in relationships were reported to not meet their life goals or to improve as much as singles and to be only slightly less satisfied and happy with their lives compared with people who were single.

Research evaluation. After reading the research conclusions, participants also read a series of criticisms about the research, as well as rebuttals purportedly written by the study researchers. Next, participants were reminded that sometimes research can be high or low in quality and that people can agree or disagree with research. Participants were subsequently given an opportunity to provide criticisms of the research. Specifically, participants were asked to "Please list reasons why you think this study did not support its conclusion, if any. You may list as many reasons as you would like, or none at all." We focused on negative evaluations, as past studies have found that people devote more time and effort when criticizing evidence that may be unfavorable (Edwards \& Smith, 1996). Evaluations were coded for the number of reasons provided. One male and one female coder, blind to system threat condition, independently counted the number of unique reasons listed by participants. As a small number of participants explicitly referred to different research conclusions in their evaluations, it was not possible for coders to be blind to the relationship ideology manipulation. No participant, however, made any reference to the details of the system threat manipulation in their research evaluations. A reason was defined as constituting one specific idea and could include either general remarks (e.g., "Standard, tried-and-true methodology") or more specific comments (e.g., "The researcher should have performed this research on a much wider range of age groups"). Given that such measures are highly susceptible to how much a given individual tends to write, we also provided space for participants to write positive evaluations of the research findings (i.e., reasons why the study did support its conclusion), so that we could control for individual differences in writing style. The order was counterbalanced with the negative evaluations.
Interrater reliabilities between coders for evaluations were good $(\alpha s \geq .94)$. Given the acceptable level of reliability, the coders' scores were averaged for data analyses.

\section{Results}

We hypothesized that to the extent that committed relationship ideology is defended to justify the overall sociopolitical system, participants should criticize the research most when it challenges traditional relationship ideology and they are under system threat. Preliminary analyses in this and all later experimental studies revealed that, consistent with past research (Morris et al., 2008), participants' relationship status did not reveal any main effects or interactions. This was also the case for counterbalancing the positive and negative research evaluations, and thus these conditions were collapsed in the reported analyses.

To test our main hypothesis, the coded negative research evaluations were first submitted to a 2 (system threat: low vs. high) $\times$ 2 (relationship ideology support: not supported vs. supported) analysis of covariance (ANCOVA), controlling for individual differences in writing style as indicated by the positive evaluations. There were no main effects of system threat $(F<1, n s)$ or relationship ideology support, $F(1,93)=2.36, p=.13$. The results also did not reveal the predicted interaction $(F<1, n s)$. We then tested whether gender may moderate our hypothesized interaction, using a 2 (system threat) $\times 2$ (relationship ideology support) $\times 2$ (gender: female vs. male) ANCOVA. The three-way interaction was significant, $F(1,87)=6.81, p=.01$. We further probed the three-way interaction by conducting a separate 2 (system threat) $\times 2$ (relationship ideology support) ANCOVA for women and for men. Estimated means and standard errors can be seen in Table 1. There were no main effects of relationship ideology support or system threat (all $F \mathrm{~s}<1.53, n s$ ). For women, there was also no overall significant interaction, $F(1,49)=2.23$, $p=.14$, but for men, the two-way interaction was significant, $F(1$, $37)=5.20, p=.03$, and unfolded in the predicted direction.

As seen in Figure 1, when system threat was low, men did not criticize the research more or less as a function of whether the research supported traditional relationship ideology $(F<1, n s)$. However, under conditions of high system threat- that is, when system justification needs were most salient—men offered significantly more criticisms of the research when it did not support relationship ideology than when it did, $F(1,18)=7.44, p=.01$. Although our principal measure was based on coded evaluations of total number of arguments, a very similar pattern or results

Table 1

Estimated Means and Standard Errors of Negative Evaluations, Study 1

\begin{tabular}{|c|c|c|c|c|c|c|c|c|}
\hline \multirow{3}{*}{$\begin{array}{l}\text { Relationship } \\
\text { ideology }\end{array}$} & \multicolumn{4}{|c|}{ System threat for men } & \multicolumn{4}{|c|}{ System threat for women } \\
\hline & \multicolumn{2}{|c|}{ Low } & \multicolumn{2}{|c|}{ High } & \multicolumn{2}{|c|}{ Low } & \multicolumn{2}{|c|}{ High } \\
\hline & $M$ & $S E$ & $M$ & $S E$ & $M$ & $S E$ & $M$ & $S E$ \\
\hline Supported & 1.63 & 0.41 & 0.92 & 0.40 & 1.15 & 0.38 & 1.96 & 0.33 \\
\hline Not supported & 1.23 & 0.39 & 2.19 & 0.41 & 2.06 & 0.35 & 1.72 & 0.38 \\
\hline
\end{tabular}




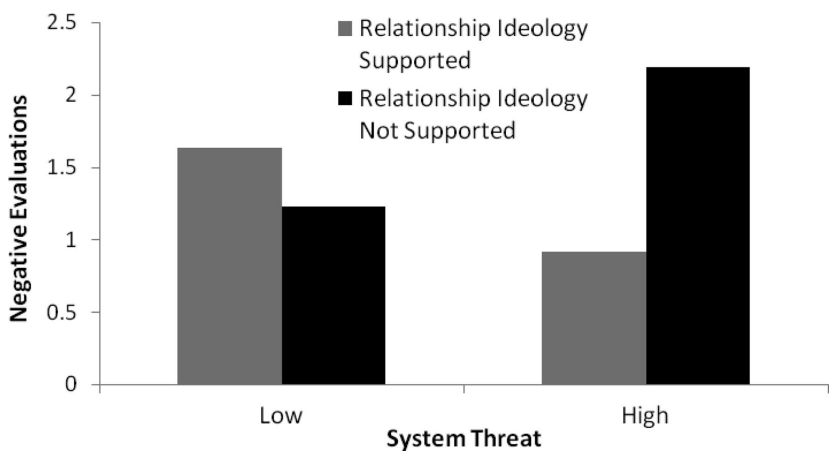

Figure 1. Men's mean negative evaluation of research that either supported or did not support relationship ideology as a function of low or high system threat, Study 1.

emerged when conducting the same analyses on the total number of words used in the evaluations. ${ }^{2}$

\section{Discussion}

Study 1 provided preliminary support for our hypothesis that defense of relationship ideology may be due, in part, to the system justification motive. For men, high system threat led to more critical evaluations of research that did not support relationship ideology, when compared with research that did support relationship ideology. Importantly, men were not simply more critical of everything following a heightened system justification motive, or more critical whenever research findings did not support the value of relationships. Increased criticisms occurred only when the system justification motive was heightened and traditional beliefs in the value of relationships were challenged.

Women's defense of relationship ideology did not strengthen as a function of the system justification manipulation. On the one hand, this gender moderation could reflect authentic differences in the extent to which relationship ideology defense is associated with the system justification motive for men versus women. On the other hand, this result could be spurious and perhaps due to a peculiarity of the study method. The system threat manipulation employed was different from the one typically used in past system justification research and focused on discrimination toward men more so than women. It is therefore conceivable that men may have found this information more relevant than women. Thus, in Study 2 we used a manipulation that earlier research has shown to induce the system justification motive in both men and women (Cutright, Wu, Banfield, Kay, \& Fitzsimons, 2011; Kay et al., 2009; Lau, Kay, \& Spencer, 2008).

\section{Study 2}

\section{Method}

Participants. One hundred and eighteen participants (61 women, 57 men; $M=21.33$ years) were recruited from the University of Waterloo campus and participated in exchange for a chocolate bar. Participants' relationship status was as follows: 44 were involved in romantic relationships averaging 21.42 months in length $(S D=16.62), 72$ identified as being single, and two did not disclose. Larger ethnic groups included 50.8\% White, 28\% Asian, and $5.1 \%$ East Indian.

Procedure. The procedure and materials were nearly identical to those of Study 1 except for the manipulation of system threat. Whereas in Study 1 we used a manipulation involving discrimination and unfair treatment of a specific group, in Study 2 we opted to employ a more general system threat manipulation. Specifically, participants were first instructed to read one of two possible magazine articles on the subject of Canadian society in general. The articles were adapted from Kay et al. (2005) and included a brief description of the current state of Canadian society as suffering economically, politically, and socially relative to other countries (high system threat) or functioning well (low system threat).

Next, the same manipulation of relationship ideology and dependent measure were employed as in Study 1. We again expected that to the extent that committed relationship ideology is defended to justify the overall sociopolitical system, following high (but not low) system threat participants will be more likely to defend relationship ideology.

Evaluation coding. Positive and negative evaluations were coded using the same procedure as in Study 1. Reliability between coders was good ( $\alpha$ s $\geq .95$ ); thus, mean coded evaluations were used in the subsequent analyses.

\section{Results}

As in Study 1, we conducted a 2 (system threat) $\times 2$ (relationship ideology support) $\times 2$ (gender) ANCOVA on the coded negative evaluations, with positive evaluations as the covariate. There was a marginal main effect of system threat, $F(1,109)=$ $3.61, p=.06$, but no main effect of relationship ideology support, $F(1,109)=2.12, p=.15$. As in Study 1 , the three-way interaction between threat, gender, and study condition was again significant, $F(1,109)=4.64, p=.03$. Means and standard errors appear in Table 2.

To decompose the three-way interaction we conducted a separate 2 (system threat) $\times 2$ (relationship ideology support) ANCOVA for women and for men. For women, there was a marginal main effect of system threat, $F(1,56)=3.68, p=.06$, such that across conditions women offered more negative evaluations after high (vs. low) threat. The interaction for women was again not significant, $F(1,56)=2.55, p=.12$. For men, there was a main effect of relationship ideology support, $F(1,52)=9.22$, $p=.004$, and the predicted interaction, $F(1,52)=2.84, p=.06$.

As seen in Figure 2, we found very similar results to Study 1. In conditions of high system threat, men offered more negative evaluations of research that did not support relationship ideology compared with research that supported relationship ideology, $F(1$, $31)=14.48, p=.001$. In conditions of low system threat, no such differences emerged $(F<1, n s)$. As in Study 1 , we conducted the

\footnotetext{
${ }^{2}$ The two different measures-coded evaluations and total words used-revealed relatively high convergence $(r \mathrm{~s} \geq .77, p \mathrm{~s}<.001)$. When we conducted ANCOVA analyses using the total number of words used, the three-way interaction was significant. When split by gender, the twoway interaction was significant for men but not women. Finally, the pattern and significance of the simple effects for men mimicked those found when using coded evaluations.
} 
Table 2

Estimated Means and Standard Errors of Negative Evaluations, Study 2

\begin{tabular}{|c|c|c|c|c|c|c|c|c|}
\hline \multirow{3}{*}{$\begin{array}{l}\text { Relationship } \\
\text { ideology }\end{array}$} & \multicolumn{4}{|c|}{ System threat for men } & \multicolumn{4}{|c|}{ System threat for women } \\
\hline & \multicolumn{2}{|c|}{ Low } & \multicolumn{2}{|c|}{ High } & \multicolumn{2}{|c|}{ Low } & \multicolumn{2}{|c|}{ High } \\
\hline & $M$ & $S E$ & $M$ & $S E$ & $M$ & $S E$ & $M$ & $S E$ \\
\hline Supported & 1.21 & 0.38 & 0.99 & 0.31 & 1.10 & 0.27 & 2.21 & 0.33 \\
\hline Not supported & 1.45 & 0.33 & 2.19 & 0.28 & 1.55 & 0.29 & 1.65 & 0.36 \\
\hline
\end{tabular}

same analyses using raw word counts for the criticism section as the dependent measure. Again, the same three-way and two-way interactions emerged, in which the predicted effect surfaced only for men.

\section{Discussion}

The results of Study 2 were very consistent with those of Study 1. Our hypothesized pattern of results was again found among men but not women. Using a different manipulation of system threat, we observed that men, but not women, increasingly defended relationship ideology following system threat, providing more negative evaluations of research findings that did not support relationship ideology. Again, men were not simply more critical of everything following system threat, nor were they more critical whenever research findings did not support the value of relationships. Rather, increased criticisms occurred only when the system justification motive was heightened and traditional beliefs in the value of relationships were challenged.

Although we did not predict this pattern of gender moderation, the converging evidence from Studies 1 and 2 strongly suggests our original hypothesis may apply more to men than women. We continue, however, to include both men and women in the remaining studies we present, so as to assess the consistency of this pattern of gender moderation.

In Study 3 we used an alternative, yet conceptually similar, approach to examine whether system justification motives may be involved in relationship beliefs. If, as we suggest, relationship ideology is supported and defended because it is associated with the overarching sociopolitical system that people are motivated to defend, then just as threatening the generalized system leads to increased defense of relationship ideology, threatening the system of committed relationships should lead to increased defense of the overarching sociopolitical system. Given the results of Studies 1 and 2, we suspect this might occur only for male participants.

We believe relationship ideology threat will influence attitudes toward the overall system because these are both systems that are relevant to the sociopolitical hierarchy within which our participants exist. To be more certain that our findings reflect this specific association, and not a simple tendency to just bolster anything after threat, we also included a measure that taps attitudes toward a system mostly irrelevant to the participants' lives: the entertainment industry. The functioning of this unrelated system has little influence on the social order of the participants' lives. Thus, if we find that men more resolutely defend the sociopolitical system, but not the entertainment system, following a threat to relationship ideology, we can be more confident that this effect is due to the system justification motive.

\section{Study 3}

\section{Method}

Participants. Fifty-nine participants (28 women, 31 men; $M=20.57$ years) were recruited from the University of Waterloo campus and participated in exchange for a chocolate bar. Twentythree were involved in romantic relationships averaging 28.22 months in length $(S D=65.74)$, and 36 identified as being single. Larger ethnic groups included 54.2\% White, 22\% Asian, and 10.2\% Middle Eastern.

Procedure. Participants volunteered for a study on "media and politics." After agreeing to participate, an experimenter, who was blind to condition, gave participants a booklet containing the study materials. Participants were asked to follow the directions carefully and complete the materials on their own. Participants first read and evaluated an article designed to threaten the stability of the institution of committed relationships. Afterward, participants were asked about their opinions on politics in general, as well as on the entertainment industry. The former was measured via an established measure of system support (Kay \& Jost, 2003), and the latter served as an unrelated comparison system.

Committed relationship ideology threat. Participants were exposed to information that suggested the institution of committed relationships was either stable and strong (low relationship ideology threat) or unstable and fragile (high relationship ideology threat). Participants in the high threat condition were asked to read a newspaper article titled "The Era of 'Not So' Committed Relationships." The article depicted the trend of divorce rates, as well the number of people remaining single, as increasing. It suggested that this may be the case because people no longer valued committed relationships as much as in the past. In the low threat condition, participants were exposed to a very similarly worded newspaper article, titled "The Era of Committed Relationships," but with an emphasis on the continuation of committed relationships. Participants read that many marriages and committed relationships succeed and that despite divorce being more freely allowed, monogamy is a still a viable and valued option.



Figure 2. Mean level of negative evaluation by men following exposure to research that supported or did not support relationship ideology for low and high system threat conditions, Study 2 . 
Dependent measures. After reading the newspaper article, participants were asked their opinions on politics and entertainment. These measures indexed endorsement of the Canadian sociopolitical system and endorsement of an irrelevant system-the entertainment industry. For the former, an established measure of sociopolitical system support was employed (Kay \& Jost, 2003), in which participants were asked to indicate their agreement with eight system-justifying statements $(\alpha=.87)$ on a 9-point scale $(1=$ strongly disagree, $9=$ strongly agree $)$. Example statements included "In general, Canadian society is fair" and "Canadian society needs to be radically restructured" (reverse scored). For the latter, a five-item measure of the entertainment industry was created $(\alpha=.60)$, in which participants were asked to indicate their agreement with five statements regarding the functioning of the entertainment industry. Example items included "The music business does a good job at promoting its musicians" and "The entertainment industry is managed very carefully."

\section{Results}

A 2 (system type: sociopolitical vs. entertainment) $\times 2$ (relationship ideology threat: low vs. high) $\times 2$ (gender: female vs. male) mixed analysis of variance (ANOVA) was conducted with repeated measures on the first variable. We hypothesized that compared with a low threat to the system of committed relationships, following a high threat, men, but not women, should show heightened defense of the sociopolitical system. We also hypothesized that these same threats to the committed relationship system would not influence defense of a theoretically unrelated system. Results revealed that there was a within-participant main effect for the type of system condition, $F(1,55)=11.94, p=.001$, which indicated generally higher endorsement scores for the sociopolitical system $(M=5.98, S E=0.16)$ than the entertainment system $(M=5.31, S E=0.16)$. Importantly, the predicted three-way interaction also attained significance, $F(1,55)=3.95, p=.05$. Means and standard errors can be found in Table 3 .

To further examine our hypothesis, we conducted a separate 2 (system type) $\times 2$ (relationship ideology threat) mixed-model ANOVA for women and for men. Results revealed that, again, the two-way interaction was not significant for women $(F<1, n s)$ but was significant for men, $F(1,58)=4.44, p=.04$. As seen in Figure 3, the interaction unfolded as predicted for male participants. Those in the high relationship ideology threat condition endorsed the sociopolitical system to a greater extent than did those who learned that relationships were not under threat, $F(1,29)=7.44, p=.01$. The threat manipulations had no effect on men's endorsements of the irrelevant entertainment system $(F<1, n s)$.

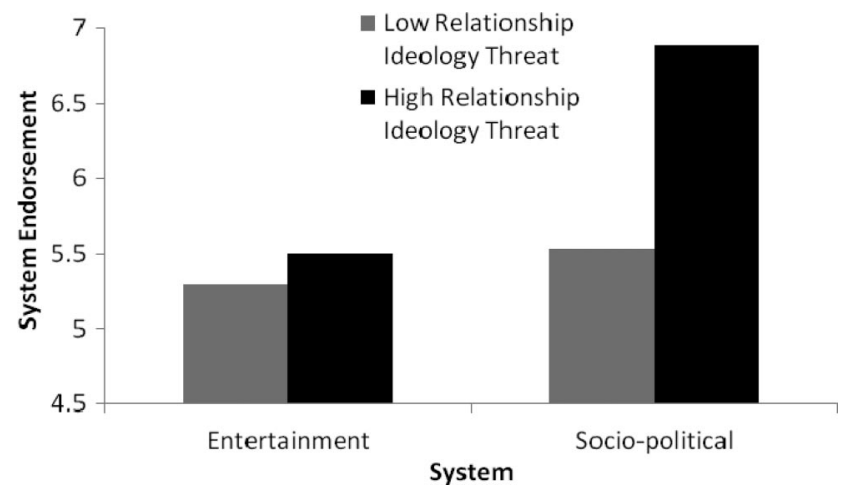

Figure 3. Men's mean level of system endorsement following exposure to low versus high relationship ideology threat, Study 3.

\section{Discussion}

We have proposed that the institution of committed relationships, as a component of the broader sociopolitical system, is defended so staunchly at least in part because it represents a means of satisfying the system justification motive. In support of this reasoning, Studies 1 and 2 demonstrated that, for men, threatening the legitimacy of the sociopolitical system increased defense of committed relationship ideology. However, if relationship defense and generalized system defense both satisfy the same motive, then this relationship should be bidirectional: Threatening the system of committed relationships should increase defense of the generalized sociopolitical system. The results of Study 3 support this logic. Following a threat to committed relationship ideology, men bolstered support for the overarching sociopolitical system. This did not occur, however, for women. It also did not occur when we measured responses to an irrelevant system, the entertainment industry.

This predicted null effect for our system-irrelevant measure, however, should be interpreted with caution, as its internal consistency was only mediocre. This introduces the possibility that an effect was not observed for this measure because of the looseness of the relationship among the individual items. Two observations, however, limit our concern in this regard. First, there were no effects of the threat manipulation on any of the five individual items (all $F \mathrm{~s}<1.14, n s$ ). This suggests that the lack of an overall effect across the items was not due to noise introduced by some of the specific items. Second, because of the low alpha, we conducted follow-up analyses on a separate sample of participants $(N=36)$ who were exposed to the same relationship ideology manipulation

Table 3

Means and Standard Errors of System Endorsement, Study 3

\begin{tabular}{|c|c|c|c|c|c|c|c|c|}
\hline \multirow[b]{3}{*}{ Relationship ideology threat } & \multicolumn{4}{|c|}{ System for men } & \multicolumn{4}{|c|}{ System for women } \\
\hline & \multicolumn{2}{|c|}{ Entertainment } & \multicolumn{2}{|c|}{ Sociopolitical } & \multicolumn{2}{|c|}{ Entertainment } & \multicolumn{2}{|c|}{ Sociopolitical } \\
\hline & $M$ & $S E$ & $M$ & $S E$ & $M$ & $S E$ & $M$ & $S E$ \\
\hline Low & 5.29 & 0.30 & 5.53 & 0.29 & 4.75 & 0.33 & 5.54 & 0.32 \\
\hline High & 5.50 & 0.33 & 6.88 & 0.32 & 5.63 & 0.33 & 5.98 & 0.32 \\
\hline
\end{tabular}


but evaluated a different unrelated system. These participants were asked to rate the legitimacy of a company that was different from their own place of employment, but where they knew an employee. Using rating scales, they indicated how well the company was operating and how fair and equally it treated its employees (four items, $\alpha=.94)$. This measure was also unaffected by the relationship ideology threat $(F<1, n s)$.

The results of Studies $1-3$, therefore, provide converging support for our modified hypothesis. Across these three studies we have observed that, for men, threats to the legitimacy of the sociopolitical system influence the defense of relationship beliefs, and threats to relationship ideology influence the defense of the generalized sociopolitical system. In other words, for men but not women, relationship ideology appears to be intertwined with broader system justification needs.

\section{Study 4}

Past work on system justification has demonstrated that systems are defended, in part, because they provide a sense of predictability and order in a sometimes unpredictable world - that is, they can serve as an external source of control (Jost \& Hunyady, 2005; Kay \& Jost, 2003; Kay, Shepherd, et al., 2010; see also Lerner, 1980). Thus, a more specific way to examine whether the system justification motive influences the defense of committed relationship values would be to assess whether perception of relationships as a means of external control contributes to the defense of this ideology. We define control as the order, structure, and predictability that relationships can potentially provide people's lives. By imbuing people's lives with order and structure, relationships can represent another external system that suggests that what happens to a given individual, whether good or bad, is not random but instead controlled by clearly defined systems. As such, believing in traditional relationship ideology may represent a useful means of protecting oneself from uncertainty and randomness, just as is the case with other religious and political systems (Kay, Gaucher, McGregor, \& Nash, 2010). This version of control aligns with close relationship research, where relationships are often discussed in terms of the security and stability they bring to people's lives (e.g., Mikulincer \& Shaver, 2005).

If the potential control and order provided by relationships do in fact contribute to the defense of this institution, then we should observe increased relationship defense amongst those led to believe that relationships indeed offer more control. In addition, if this effect is due to the same motivational system observed in Studies 1-3, then it should occur most strongly for men. Study 4 tests these propositions.

\section{Method}

Participants. Ninety undergraduates (45 women, 45 men; $M=21.88$ years) participated in exchange for a chocolate bar or as partial fulfillment of course credit. Forty-four were involved in romantic relationships averaging 29.35 months in length $(S D=$ 29.75), 45 identified themselves as single, and one did not disclose. Larger ethnic groups included 45.6\% White, 42.2\% Asian, and $7.8 \%$ East Indian.

Procedure. Participants were asked to read and evaluate research materials ostensibly for a psychology textbook being designed for high school students. Specifically, the textbook authors wanted university students' opinions on what would be most interesting and relevant. Participants were told that the materials would be on the topics of relationships and positive psychology.

Manipulation of relationship control. Participants were first asked to read a research abstract about relationships. This abstract presented results that suggested relationships can control wellbeing and offer order and stability (relationships exert control) or that found no such association (relationships do not exert control). In the relationships exert control condition, participants read the following:

According to a vast array of research, people's level of happiness is strongly connected with the quality of their committed relationships. According to research on dating and married couples by Holmes (2004), whether peoples' relationship functions smoothly or not in large part will determine their happiness; successful relationships breed more happiness and unsuccessful relationships breed less happiness. Surprisingly, the influence of relationship quality for personal happiness is considerably stronger than the influence of work or leisure activities on happiness. Also, peoples' sense of stability and order depends on the quality of their relationship.

In the relationships do not exert control condition the abstract was similar, but without the control-related associations of relationships. Participants read that people's level of happiness is not connected with the quality of their committed relationships, and instead overall happiness is tied more closely to domains related to their identities, such as work or leisure.

Test of relationship control manipulation. We conducted a pilot study $(N=28)$ to assess whether our manipulation had the intended effects, that is, whether the manipulation did increase participants' sense that relationships, in general, do exert control and provide structure to people's lives, but do not influence perceptions of the positivity of participants' own personal relationships. Pilot participants in the relationships exert control condition indicated that, if they were in a committed relationship, their level of happiness would be more based on the good or bad quality of the relationship, $t(26)=3.29, p=.003$, and less based on factors external to the relationship, $t(26)=2.55, p=.02$, than those in the relationships do not exert control condition. In other words, participants in the relationships exert control condition perceived well-being as more dependent on relationships. Furthermore, participants did not differ as function of condition when asked whether their personal committed relationship would be of high quality, $t(26)=0.48, p=.63$, or would bring them happiness, $t(26)=1.16, p=.26$. Together, these findings indicate that the manipulation strongly heightened participants' beliefs that relationships do exert control over people's lives, without influencing general positive expectations of participants' own relationships.

Committed relationship ideology. Participants were told that textbook authors purportedly wanted to better understand how representative a previously collected sample of opinions on committed relationships were of the population (for use in the textbook). Participants were then asked to read each opinion and indicate how much they personally agreed with the statement $(1=$ strongly disagree, $9=$ strongly agree). These 12 opinion items comprised our measure of committed relationship ideology endorsement $(\alpha=.81)$. The statements were designed to be characteristic of committed relationship ideology, as described by De- 
Paulo and Morris (2005). The measure included statements such as "Most of my single friends would be better off in a committed relationship," "There are very few major downsides to being in a committed relationship," "The concept of a committed relationship is the ultimate answer," "Committed relationships are overrated" (reverse scored), "Single people are missing out," and "Becoming involved in a committed relationship is the right thing to do."

\section{Results}

Committed relationship ideology scores were submitted to a 2 (relationship control: exert control vs. do not exert control) $\times 2$ (gender: female vs. male) between-subjects ANOVA. Means and standard deviations can be seen in Table 4. We hypothesized that men's endorsement of relationship ideology would be higher when participants were led to believe that relationships do exert control over their lives, compared with when they were led to believe they do not. No effect was expected for women.

Results indicated a main effect of the manipulation, $F(1,86)=$ $4.08, p=.05$, such that participants in the relationships exert control condition endorsed relationship ideology to a greater extent than did participants in the relationships do not exert control condition. There was also a main effect of gender, $F(1,86)=3.91$, $p=.05$, indicating that men supported relationship ideology more than did women. However, as seen in Figure 4, these main effects were qualified by the predicted Gender $\times$ Condition interaction, $F(1,86)=4.16, p=.04$. Simple effects analyses revealed that although women's endorsements of relationship ideology were not affected by the experimental manipulation $(F<1$, ns), men endorsed relationship ideology more strongly when relationships were framed as exerting control, compared with when they were framed as not exerting control, $F(1,43)=7.27, p=.01$.

\section{Discussion}

In Study 4, we hypothesized that one reason why the defense of committed relationship ideology may be connected with the broader system justification motivation is because relationships, like other aspects of the sociopolitical system, provide people with a sense of order and structure. Results confirmed our predictions. Participants led to believe that relationships offered control and structure more strongly supported committed relationship ideology than did participants led to believe relationships do not offer control and structure. As in Studies 1-3, this effect was found for men but not women, suggesting the same general process observed in Studies 1-3 is again occurring.

Why, across these four studies, have we consistently observed effects for men but not women? That is, why might relationship

Table 4

Means and Standard Deviations of Relationship Ideology Endorsement, Study 4

\begin{tabular}{|c|c|c|c|c|}
\hline \multirow[b]{2}{*}{ Condition } & \multicolumn{2}{|c|}{ Men } & \multicolumn{2}{|c|}{ Women } \\
\hline & $M$ & $S D$ & $M$ & $S D$ \\
\hline Relationships exert control & 5.97 & 1.04 & 5.04 & 1.03 \\
\hline Relationships do not exert control & 5.03 & 1.28 & 5.04 & 1.01 \\
\hline
\end{tabular}

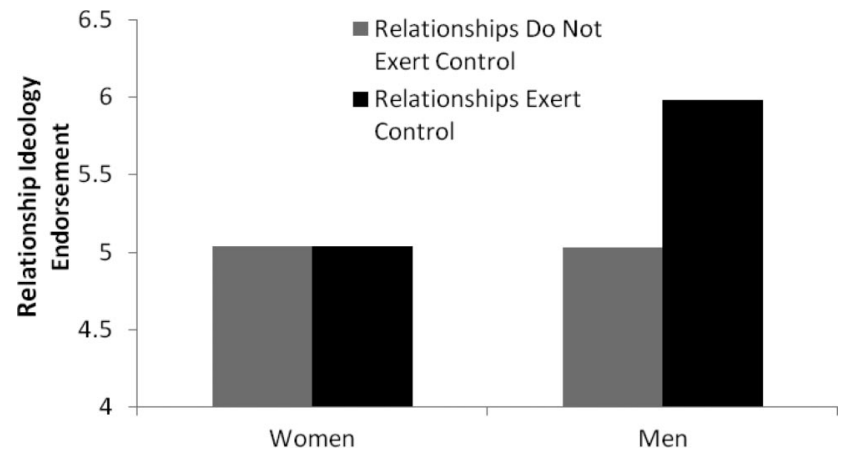

Figure 4. Men and women's mean relationship ideology endorsement as a function of relationships that exert control and relationships that do not exert control, Study 4.

ideology be associated with broader system justification needs for men more so than women? One potential explanation for the repeated gender moderation could be that women were simply higher than men in their support of relationship ideology and that, therefore, men had room to increase their scores following the system threat manipulation but women did not. Women and men, however, were not evincing greatly different levels of support for relationship ideology in these studies; men were simply more responsive to the system manipulations than women, making such an explanation unlikely.

A more promising explanation may be that for men the traditional system of relationships is a key component to maintaining their social and economic advantage relative to women. Given that relationships, along with many other aspects of the social, political, and economic system, tend to confer considerable power advantages to men (Jackman, 1994), a threat to the traditional relationship dynamic may be more psychologically threatening to the broader type of system men hope to maintain, that is, one that advantages them (Sidanius \& Pratto, 1999). This is consistent with psychology of gender theorists who have discussed the multitude of ways in which traditional forms of gender relations benefit men more than women (e.g., Glick \& Fiske, 2001; Rudman \& Glick, 1999). As such, for men, but not necessarily women, the traditional system of gender relationships may be strongly linked to their general beliefs about the status quo, whereas for women, their beliefs about gender relationships may be separate from their broader political beliefs, related perhaps more to their personal identities (a possibility we examine in Studies 6 and 7).

If this is in fact the case, then the relationship between support for the sociopolitical system and relationship ideology for men may be strongest in contexts in which the traditional male advantage is most precarious and under threat-namely, cultures with the highest levels of gender equality. In other words, as women receive more equal rights, pay, positions of status, and so on, advantages diminish for men, and they may be more likely to defend institutions that can help preserve their advantage. In Study 5 , we tested this notion. We also sought to examine if the findings from Studies 1-4 would conceptually replicate correlationally and cross-culturally.

To do so, we assessed motivations to defend the political system, defense of committed relationships (i.e., marriage), and country-wide levels of gender equality in 29 countries. A three- 
way interaction, in which system-justifying beliefs (i.e., defense of the political system) predict defense of the institution of marriage most strongly for men (compared with women) in contexts of relatively high (compared with relatively low) levels of gender equality, was hypothesized.

\section{Study 5}

\section{Method}

We analyzed data from the fourth wave of the World Values Survey (2006), which was administered from 2000 to 2004. Data for our variables of interest were available for nationally representative samples from 29 different countries, yielding a total of 33,018 respondents. Table 5 lists the nations used in our analysis.

We used the United Nations Development Programme's (UNDP; 2000) Gender Empowerment Measure as our measure of national gender inequality. The Gender Empowerment Measure is a composite indicator that captures gender inequality in political decision making (e.g., percentage of parliamentary seats held by

Table 5

GEM Ratings, Political System Ratings, and Frequency of Those Who Defend (vs. Reject) the Institution of Marriage for 29 Countries From the World Values Survey

\begin{tabular}{|c|c|c|c|c|}
\hline \multirow[b]{2}{*}{ Country } & \multirow[b]{2}{*}{ GEM } & \multicolumn{2}{|c|}{$\begin{array}{c}\text { Political } \\
\text { system rating }\end{array}$} & \multirow{2}{*}{$\begin{array}{c}\% \text { defend (vs. reject) } \\
\text { marriage }\end{array}$} \\
\hline & & $M$ & $S D$ & \\
\hline Jordan & .22 & 6.02 & 2.26 & 87.5 \\
\hline Turkey & .32 & 2.91 & 2.03 & 91.4 \\
\hline Romania & .41 & 3.66 & 2.30 & 87.5 \\
\hline Ukraine & .42 & 3.40 & 1.94 & 82.7 \\
\hline Russian Federation & .43 & 2.57 & 1.69 & 79.4 \\
\hline Peru & .45 & 5.56 & 2.47 & 80.0 \\
\hline Greece & .46 & 4.80 & 2.00 & 84.3 \\
\hline Hungary & .49 & 3.95 & 1.88 & 83.8 \\
\hline Poland & .51 & 3.98 & 1.91 & 90.9 \\
\hline Croatia & .52 & 3.37 & 1.95 & 85.3 \\
\hline Italy & .52 & 4.26 & 1.89 & 83.0 \\
\hline Slovenia & .52 & 4.39 & 1.91 & 72.6 \\
\hline Lithuania & .53 & 3.22 & 2.09 & 79.5 \\
\hline Slovakia & .53 & 3.81 & 1.85 & 88.5 \\
\hline Czech Republic & .54 & 4.33 & 1.80 & 84.4 \\
\hline Estonia & .54 & 4.70 & 1.73 & 83.7 \\
\hline Latvia & .54 & 4.37 & 1.73 & 83.6 \\
\hline Ireland & .59 & 5.76 & 2.10 & 79.5 \\
\hline Spain & .62 & 5.65 & 1.90 & 79.1 \\
\hline Portugal & .62 & 5.90 & 1.75 & 75.4 \\
\hline Great Britain & .66 & 5.26 & 1.77 & 72.8 \\
\hline Austria & .71 & 5.78 & 1.89 & 81.0 \\
\hline Belgium & .73 & 4.81 & 1.94 & 69.1 \\
\hline Netherlands & .74 & 6.28 & 1.41 & 74.7 \\
\hline Finland & .76 & 5.87 & 1.79 & 80.9 \\
\hline Germany & .76 & 6.08 & 2.05 & 79.8 \\
\hline Denmark & .79 & 5.12 & 2.02 & 78.8 \\
\hline Sweden & .79 & 5.18 & 1.95 & 79.8 \\
\hline Iceland & .80 & 6.05 & 1.72 & 89.2 \\
\hline
\end{tabular}

Note. Ratings on the United Nation's Gender Empowerment Measure (GEM) range from 0 to 1 , where $0=$ absolute inequality and $1=$ absolute equality. Political system ratings were made on a 1 to 10 scale, where $1=$ very bad and $10=$ very good. women) and economic participation (e.g., women's share of earned income; UNDP, 2000, p. 168). The overall index ranges from 0 to 1 , such that 0 denotes complete gender inequality and 1 denotes complete gender equality.

Gender was dummy coded such that $0=$ male and $1=$ female. Rating of the political system was assessed with a single item that read,

People have different views about the system for governing this country. Here is a scale for rating how well things are going: "1" means very bad; "10" means very good. Where on this scale would you put the political system as it is today?

Defense (vs. rejection) of marriage was assessed with a single item that asked respondents whether they agreed or disagreed with the statement "Marriage is an outdated institution." Responses were coded such that $0=$ agree and $1=$ disagree. The descriptive statistics for these latter two variables can be seen in Table 5.

In addition to our variables of interest, we adjusted for several demographic variables in our model, including income (three intervals), education (three intervals), age (six intervals), and marital status (dummy codes for single, divorced, and widowed, compared with married). In addition, we adjusted for the natural log of each country's gross domestic product per capita (GDP) on the nation level. All of the non-dummy-coded variables in the model were centered on their group mean.

\section{Results}

We conducted a random and fixed effects logit-linked multilevel model predicting the defense (vs. rejection) of marriage with national level of gender equality, the political system rating, gender, and all two- and three-way interactions of these variables, as well as the adjustment variables. As shown in Table 6, after adjusting for national wealth (i.e., GDP), there was no main effect of national level of gender equality on marriage defense $(b=.25$, $S E=.57, n s)$. Women were more likely than men to endorse the idea of marriage $(b=.15, S E=.02, p<.001)$; this was true regardless of the societal context, as shown by the nonsignificant interaction between gender and national gender equality $(b=.03$, $S E=.11, n s)$. In addition, results revealed that there was a significant positive relationship between political system ratings and defense of marriage $(b=.05, S E=.01, p=.001)$. This was further qualified by significant two-way interactions with gender $(b=-.03, S E=.01, p=.01)$ and national gender equality $(b=$ $.29, S E=.04, p=.001)$, as well as the predicted significant three-way interaction between these variables $(b=-.14, S E=.03$, $p=.001)$. We probed the two- and three-way interactions at high and low levels of national gender equality (1SD above and below our sample mean) for both men and women using the online tools provided by Preacher, Curran, and Bauer (2006). As seen in Figure 5, results revealed that in countries with low gender equality, there was no reliable relationship between political system rating and defense of marriage among men $(b=.01, S E=.01, n s)$ or women $(b=.00, S E=.01, n s)$. In countries with high gender equality, by contrast, the political system rating was positively and significantly associated with marriage defense. Simple slopes analyses showed that this relationship was stronger among men $(b=$ $.09, S E=.01, p=.001)$ compared with women $(b=.04, S E=$ $.01, p=.001)$ 
Table 6

Estimated Fixed Effects (and Robust SEs) From a Random and Fixed Effects Population-Average Nonlinear (Logit) Multilevel Model Predicting Defense of Marriage in 29 Countries

\begin{tabular}{|c|c|}
\hline Predictor & Effect $(S E)$ \\
\hline \multicolumn{2}{|l|}{ Nation-level predictors } \\
\hline Intercept & $1.63(.06)^{* * *}$ \\
\hline Gender equality & $.25(.57)$ \\
\hline Gross domestic product per capita (log) & $-.34(.09)^{* * *}$ \\
\hline \multicolumn{2}{|l|}{ Individual-level predictors } \\
\hline Education & $.09(.03)^{* * *}$ \\
\hline Income & $.05(.02)^{*}$ \\
\hline Age & $.12(.02)^{* * * *}$ \\
\hline Single (vs. married) & $-.56(.05)^{* * * *}$ \\
\hline Divorced (vs. married) & $-.96(.05)^{* * *}$ \\
\hline Widowed (vs. married) & $-.09(.03)^{* * *}$ \\
\hline Female (vs. male) & $.15(.02)^{* * *}$ \\
\hline Political system rating & $.05(.01)^{* * * *}$ \\
\hline Political System Rating $\times$ Gender & $-.03(.01)^{* *}$ \\
\hline \multicolumn{2}{|l|}{ Cross-level interactions } \\
\hline Gender $\times$ Gender Equality & $.03(.11)$ \\
\hline Political System Rating $\times$ Gender Equality & $.29(.04)^{* * * *}$ \\
\hline Political System Rating $\times$ Gender $\times$ Gender Equality & $-.14(.03)^{* * * *}$ \\
\hline
\end{tabular}

\section{Discussion}

Thus, Study 5 provides both a cross-cultural, correlational replication of the pattern of data observed in Studies 1-4 as well as initial evidence for what may underlie the pattern of gender moderation we have repeatedly observed. In those countries in which the traditional dominance of men over women is most under threat, a strong association between support for the political system and defense of the institute of marriage was observed for men. A still significant, but much weaker, relationship was found for women. These results once again suggest that, for men more so than women, ideological support for the institution of marriage is interconnected with broad motivations to defend the sociopolitical system.

These findings may suggest the joint operation of both system justification and social dominance motivations. That is, men appear to be defending traditional relationship ideology not only because of its relation to the larger sociopolitical system that people are motivated to defend (Jost \& Banaji, 1994) but also because of its utility in preserving male dominance (Sidanius \& Pratto, 1999). Whereas the hydraulic relation between support for political and relational systems observed in Studies 1-4 is unique to system justification theory (e.g., Jost, Ledgerwood, \& Hardin, 2008; Kay, Shepherd, et al., 2010; Wakslak, Jost, \& Bauer, in press), the fact that this effect is strongest for men, especially when their dominance is most under threat, fits well with a social dominance approach (Sidanius \& Pratto, 1999).

But what about women? It is clear that women's endorsement of relationship ideology is not substantially affected by those variables that have typically induced the system justification motive in men and women alike. Why might this be? One possibility is that, for women, who view close relationships (e.g., romantic partner, best friend) as central to their identity (Cross et al., 2000), their attitudes toward relationships may be more influenced when they are considering their personal relationships or when threats are targeted toward them personally. Men may not have excluded relationships from their broader ideological sphere (Baumeister \& Sommers, 1997; Gabriel \& Gardner, 1999), allowing them to forge connections between their political beliefs and their relationship beliefs that women may be less likely to make. To the extent that this is so, when participants are focused on their personal relationships, an association between system-related motivations and committed relationships may exist for women. Thus, it may be the case that in response to threatening conditions of the sociopolitical system, women may turn to their own close relationships as a trusted source of security and stability, instead of to a broader committed relationship ideology.

We test this general idea in Studies 6 and 7. In Study 6, we activated the system justification motive by threatening the overarching system and then measured participants' identification with their romantic relationship instead of ideological beliefs about relationships in general. We predicted that system threat would lead to increases in identification with one's romantic relationship. We also predicted that a threat to the overarching system would result in one's romantic relationship being perceived as more secure and stable (e.g., confidence in partner's dependability, reciprocated affections), as we believe people may increase their relationship self-identification, in part, because of the perceived felt security these relationships may provide (Murray, Holmes, \& Griffin, 2000). Given that relationships are presumed to be a more important part of the self-concept for women than men (Cross et al., 2000), it may be that this effect is stronger for women than men. On the other hand, it may not. Past research has demonstrated that men and women alike rely on their close personal relationships for a sense of security and stability (Mikulincer \& Shaver, 2005). As a result, we were relatively agnostic as to whether men would show equivalent effects to women.

\section{Study 6}

\section{Method}

Participants. Ninety-five undergraduates (62 women, 33 men; $M=22.19$ years) participated in exchange for a chocolate

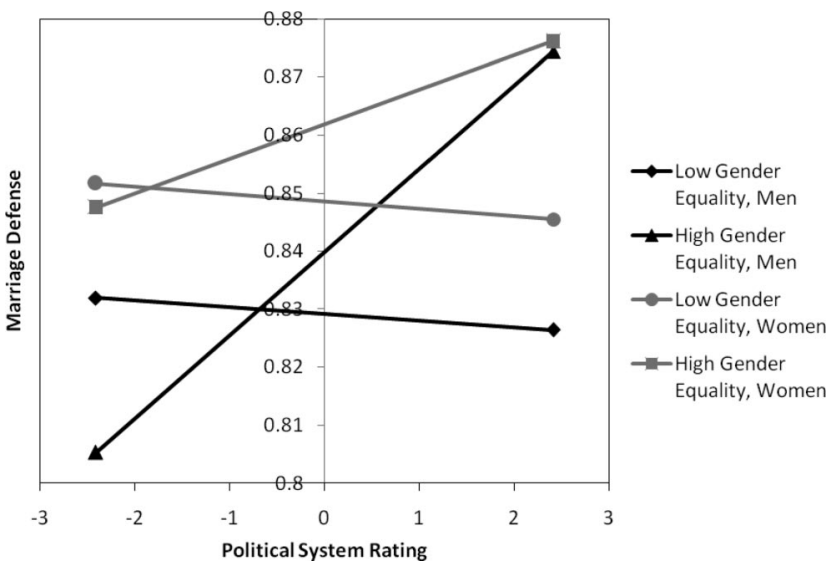

Figure 5. Defense of marriage as a function of political system rating and participant gender, at high and low (i.e., $1 S D$ above and below the mean) levels of gender equality, Study 5 . 
bar or as partial fulfillment of course credit. All participants were involved in romantic relationships averaging 30.74 months in length $(S D=50.17)$. Larger ethnic groups included $50.5 \%$ White, $31.6 \%$ Asian, and 6.3\% Middle Eastern.

Procedure. Participants volunteered for a marketing study that was ostensibly seeking people in romantic relationships for their views on the future of the newspaper industry. First, participants were asked to read and suggest a price for a newspaper article, purportedly to gauge the amount participants would be willing to pay for the article if it was made available online. To learn more about the preferences of people in relationships, participants were then asked for more extensive background information, including questions on their romantic relationship.

Manipulation of system threat. Participants were randomly assigned to read one of two newspaper articles about Canadian society. These articles were identical to the low and high system threat materials used in Study 2.

Dependent measures. Participants then completed questions about their relationship and their relationship partner. Participants completed a six-item measure of romantic relationship identity $(\alpha=.79)$. These items were based on the relational self-construal measure created by Cross et al. (2000) and adapted more specifically for romantic partners. Participants indicated how much they disagreed or agreed $(1=$ strongly disagree, $7=$ strongly agree $)$ with items such as "My romantic relationship is an important part of my identity" and "When I think of myself, I often think of my romantic partner also." In addition, participants completed a measure of relationship felt security (Marigold, Holmes, \& Ross, 2007; Murray et al., 2000). Participants were asked to consider "how you feel about your relationship right now" while they responded $(1=$ not at all true, $7=$ completely true) to 12 statements such as "I am confident that my partner will always want to look beyond my faults and see the best in me" and "My partner loves and accepts me unconditionally" $(\alpha=.92)$.

\section{Results}

We conducted a 2 (system threat: high vs. low) $\times 2$ (gender: female vs. male) ANOVA on romantic relationship identity scores. Consistent with previous research (e.g., Cross et al., 2000), there was a marginal main effect of participant gender, $F(1,91)=2.77$, $p=.10$, indicating that women's romantic relationships were a larger part of their self-identities $(M=4.71, S D=1.05)$ than men's $(M=4.32, S D=1.14)$. As predicted, participants also reported greater self-identification with their romantic relationship following high system threat $(M=4.84, S D=1.13)$ compared with low system threat $(M=4.29, S D=0.98), F(1,91)=5.95$, $p=.02$. Unlike in Studies 1-3, there was no interaction between gender and system threat conditions $(F<1, n s)$.

We also conducted a 2 (system threat) $\times 2$ (gender) ANOVA on relationship felt security. There was a main effect of gender, indicating that women reported more perceived relationship security $(M=5.76, S D=1.06)$ than did men $(M=5.26, S D=0.92)$, $F(1,91)=5.24, p=.02$. There was also a main effect of system threat, such that following high system threat romantic relationships were perceived as more secure and stable $(M=5.77, S D=$ $0.96)$ compared with low system threat $(M=5.39, S D=1.09)$, $F(1,91)=3.99, p=.05$. Again, there was no interaction with gender $(F<1, n s)$.

\section{Discussion}

In Studies 1-5 we found that, for men, committed relationship ideology is influenced by broad motivations to defend the larger sociopolitical system. For women, however, system justification motives did not affect the endorsement of relationship ideology. The goal of Study 6 was to examine whether women would be affected by system threat when we asked participants about their personal relationships rather than general relationship ideology. For both men and women, this was indeed the case.

Believing in the legitimacy of the sociopolitical system can help protect people from uncertainty and insecurity (Jost \& Hunyady, 2003). When this source of certainty and order is challenged, men, it appears, can turn to both their ideological beliefs about the system of relationships in general and their personal relationships to compensate. Although women do not appear to compensate via the defense of relationship ideology, they do turn to their personal relationships in response to system threat.

\section{Study 7}

Study 6 demonstrated that women's (along with men's) perceptions of their personal relationships are influenced by system threat, but it tells us little about what leads women to defend the institution of committed relationships as an ideology. Given that women appear to turn to their personal relationship identities under conditions of system threat, relational identity maintenance may also be a driver of their endorsement of broader relationship ideology. This was tested in Study 7, in which we expected a threat to committed relationship identity would lead to greater support for committed relationship ideology. We realize that this prediction may seem counterintuitive. One might expect that after receiving negative feedback about a particular domain (e.g., singing ability), people may protect themselves by psychologically distancing themselves from potential failure (e.g., dislike karaoke social events). However, to the extent that a committed relationship is important to people's self-definitions and is a strongly sought after personal goal, following relationship identity threat people may not psychologically disengage (Major, Spencer, Schmader, Wolfe, \& Crocker, 1998). Instead people may resist incongruent information about the self (see Fiske \& Taylor, 1991) and defensively strengthen their psychological investment in the domain of relationship ideals, thereby reaffirming commitment to their relationship-attaining goal.

In Study 7, we heightened participants' defense of their relationship identity by threatening their potential to be in a successful romantic relationship. We measured the impact of this relationship identity threat on endorsement of committed relationship ideology, as well as unrelated education and work values. We expected that following a high relationship identity threat, participants would defensively bolster their support for relationship ideology, but not their work or education values, compared with following a low relationship identity threat.

\section{Method}

Participants. Sixty-five undergraduates (32 women, 33 men; $M=20.22$ years) participated in exchange for course credit or $\$ 10$. Twenty-four were involved in romantic relationships averag- 
ing 21.29 months in length $(S D=18.21)$, and 41 identified themselves as single. Larger ethnic groups included $44.6 \%$ White, $38.5 \%$ Asian, and 3.1\% East Indian.

Procedure. Participants were informed that the researchers were interested in how personality was related to attitudes toward products and marketing. Participants first completed a personality test that was supposedly linked with other personality tests taken in a previous testing session. Participants then completed a filler task consistent with the cover story in which they rated several products (e.g., candy bars, textbooks). Next, participants viewed their personality profiles, which were designed to manipulate levels of relationship identity threat. Afterward, participants provided their opinions on marketing and general life values. In this final measure we embedded questions pertaining to committed relationship ideology as well as values of education and employment.

Manipulation of relationship identity threat. Participants viewed their personality profiles by accessing a passwordprotected account on a computer. Participants viewed their percentile rank on six dimensions of personality (e.g., need for cognition), with relationship ability (i.e., relationship identity threat) as the final dimension. The results contained a range of ranks, and each dimension included a description of what low and high scores meant. All participants were exposed to the same bogus percentile ranks in all the domains except for relationship ability. The relationship identity description was as follows:

This is your personal ability to have a good, healthy, and positive committed relationship in your life. Higher scores indicate that your romantic relationship will very likely be a successful and a positive experience, whereas lower scores indicate that your romantic relationship will most likely be unsuccessful and a negative experience.

Participants were randomly assigned to either the low or high relationship identity threat condition. We expected that receiving a relatively high rank (78th percentile) would not threaten participants' relational identities; however, a low rank (38th percentile) of relationship ability was expected to be threatening, thereby activating their motivation to maintain their belief that relationships are an important aspect of their self-concept.

Dependent measures. Following the manipulation, participants completed an opinion questionnaire on marketing and values. Within the values section, we interspersed questions related to committed relationship ideology, education, and employment amongst filler questions. All questions were answered on 9-point scales, with higher numbers indicating more endorsement or agreement.

Committed relationship ideology. Five questions were employed as our measure of committed relationship ideology $(\alpha=$ .74). One question asked participants how much they valued committed relationships. Participants also indicated how much they agreed with additional statements adapted from the committed relationship ideology measure used in Study 4. Examples include "Committed relationships improve the lives of both partners involved" and "It makes me happy when I see a close friend in a committed relationship."

Education/work values. In order to evaluate response to values unrelated to committed relationships, participants completed three questions related to education and employment $(\alpha=$ .71). Participants indicated how much they valued a full-time job and a university education. Another item assessed how much participants agreed that it is essential for people to pursue a decent education.

\section{Results}

We conducted a 2 (values: committed relationship ideology vs. education/work) $\times 2$ (relationship identity threat: low vs. high) $\times$ 2 (gender: female vs. male) mixed ANOVA with repeated measures on the first variable. There was an overall between-subjects main effect for gender, $F(1,61)=5.87, p=.02$, which indicated that women had higher committed relationship ideology and education/work scores, compared with men. There was no interaction between values and gender and no three-way interaction $\left(F_{\mathrm{S}}<1\right.$, $n s)$, but importantly, we did find an interaction between values and relationship identity threat, $F(1,61)=4.23, p=.04$. As expected, education/work values, which are presumably unrelated to relationship identity, did not vary between high $(M=7.45, S E=0.23)$ and low $(M=7.61, S E=0.22)$ relationship identity threat conditions $(F<1, n s)$. However, high relationship identity threat led to significantly greater committed relationship ideology endorsement $(M=6.85, S E=0.21)$, compared with low relationship identity threat $(M=6.22, S E=0.20), F(1,61)=4.42, p=.04$

\section{Discussion}

The results of Study 7 dovetail with the findings of Study 6. In Study 6, both men and women embraced their romantic relationships to a greater extent following activation of the system justification motive. In Study 7, we found evidence that the motivation to protect one's personal relational identity predicted support for committed relationship ideology, but not irrelevant values. Thus, whereas Studies 1-5 demonstrated that men's defense of relationship ideology is partly due to broader system justification motives, Studies 6 and 7 demonstrated that when focused on personal relationships, both men and women respond equally to system threat and defensively endorse relationship ideology.

\section{General Discussion}

In this article we tested whether the defense of relationship ideology can be explained through the same motivational systems that lead people to justify the sociopolitical system. We hypothesized that the defense of committed relationships may be explainable, at least in part, via a system justification framework in which the institution of relationships represents one aspect of the generalized sociopolitical system. That is, support of relationship ideology may be one way through which people preserve beliefs in the order and stability that their overarching system can provide.

In support of this, in Studies 1 and 2 we found that a manipulation that threatened the legitimacy of the general sociopolitical system bolstered defense of relationship ideology. In Study 3, we found that exposure to information that threatened the system of committed relationships resulted in higher support for the sociopolitical system. In Study 4, we observed that beliefs in the control and structure exerted by relationships-a construct similar to one that, in other contexts (such as the government and religion), has been observed to be a key driver of system justification phenomena-increased endorsements of relationship ideology. In Study 5 we replicated our main findings correlationally in representative 
samples from 29 countries. In each study, the expected relation between the system justification motive and relationship ideology defense was observed, but only (or most strongly) for male participants. Thus, at least for men, we found consistent and converging support for our hypothesis.

Study 5 provided an explanation for the gender difference-one that is consistent with contemporary theories of intergroup relations (Sidanius \& Pratto, 1999). As men stand to gain more from social and economic conditions, including a more traditional system of committed relationships (Jackman, 1994; Sidanius \& Pratto, 1999), they have more to lose and, thus, more reason to be defensive if the institutions that potentially assist in the maintenance of these advantages are no longer supported. In particular, as overall gender equality increases (i.e., as men's advantage over women dissipates), there may be an increased tendency for men to cling to institutions that have traditionally favored their dominance. For instance, DePaulo (2006) has noted that changes in Western society over the last several decades (e.g., control over reproduction, economic opportunities, etc.) have mostly made it easier for single women to live full and meaningful lives, rather than providing gains for men. Consistent with this perspective, in Study 5 it was observed that, for men, the relationship between support for the sociopolitical system and relationship ideology was strongest in contexts in which the traditional male advantage is most precarious-namely, cultures with the highest levels of gender equality.

Studies 6 and 7 -through focusing on the role of personal identification with romantic relationships, a domain past research has found to be more central for women (Cross et al., 2000) examined conditions in which this pattern of gender moderation disappeared. Study 6 demonstrated that when the system justification motive is heightened, both men and women increase their identification with their personal romantic relationship. Study 7 went one step further and demonstrated that, for men and women, when one's own romantic relationship identity is threatened, support for committed relationship ideology increases. Thus, although Studies 1-5 failed to yield any evidence that women directly link system justification with committed relationship values, we did find links to both these constructs through the lens of men's and women's own close relationship identity.

\section{Singles and People in Relationships}

Relationship status was the other group-level factor we examined in all but one study. Although some might expect that singles, being potentially disadvantaged by relationship ideology (e.g., DePaulo, 2006; DePaulo \& Morris, 2005), would not endorse relationship beliefs to the same extent as people in relationships, across studies our main findings were not qualified by relationship status. Embedded within committed relationship ideology is the notion that singles are not valued as much as people in relationships. The fact that our manipulations predicted support for relationship ideology, but relationship status did not, suggests this stereotype is not simply the result of outgroup derogation but serves a broader system-justifying function (e.g., Jost \& Kay, 2005; Jost, Pelham, \& Carvallo, 2002). As such, discriminatory practices against singles may have some roots in system-justifying needs. When system justification contexts are salient, our research suggests that men, even single ones, may further support beliefs that help rationalize the unequal treatment of people who are single. Furthermore, on the basis of the findings of Study 7, and similar to past research (Fein \& Spencer, 1997), a threat to men and women's relationship identities may be another context that leads to greater stereotyping and potential discrimination against singles.

Although in the present research we did not test for associations between the system justification motive and explicit discrimination against singles, this may be a promising direction for future research. For example, even without the activation of the system justification motive, past research has documented the unremorseful discrimination against singles in the search for housing (Morris, Sinclair, \& DePaulo, 2007). Furthermore, a robust finding in economic and sociological research is the higher salaries paid to married compared with single men (see Loh, 1996). Recent research suggests that this marriage wage premium cannot be well explained by overall performance, more productive men selfselecting marriage, or by additional work specialization due to less household work (Antonovics \& Town, 2004; Hersch \& Stratton, 2000). It is possible that this wage discrepancy may be at least partly due to agreement with committed relationship ideology and the application of single and married person stereotypes, implicitly or explicitly.

\section{System Justification and Relationship Identity}

One striking finding of Study 6 was that the motivation to justify the larger sociopolitical system influenced men and women's self-views involving their romantic partner and the extent to which they perceived felt security in their relationship. This suggests that psychological needs that are made salient following system threat are satiable via self-relevant relationship cognitions. It is noteworthy indeed that such macrolevel threats can exert effects on such microlevel relationships. Whereas extensive relationship research has looked at the effects of self- and individual-level threats on people's perceptions of their relationships (Mikulincer \& Shaver, 2005), the role of broad, system-level threats on relationship perception has not received much empirical attention whatsoever (see Lau et al., 2008). Although one might imagine this would be the case only for serious romantic partners, it is very possible that in response to a heightened system justification motive, people may adjust their relational self-concept surrounding any close relationship that is perceived as highly secure and stable. Discovering precisely the types of relationships that can help satiate system justification needs, as well precisely how they do so, is a potentially fruitful area for future research.

\section{Concluding Remarks}

Assumptions and beliefs about committed relationships are embedded within Western culture. Our research represents the first experimental investigation of the role of broad motivational needs in maintaining such beliefs. In this article, we have demonstrated that, at least for men, beliefs surrounding committed relationships do not exist in a vacuum. They are instead enmeshed within broader consideration of the sociopolitical system and the hierarchies it serves to maintain. 


\section{References}

Antonovics, K., \& Town, R. (2004). Are all the good men married? Uncovering the sources of the marital wage premium. American Economic Review, 94, 317-321. doi:10.1257/0002828041301876

Baumeister, R. F., \& Sommers, K. L. (1997). What do men want? Gender differences and two spheres of belongingness: Comment on Cross and Madson (1997). Psychological Bulletin, 122, 38 -44. doi:10.1037/00332909.122.1.38

Conley, T. D., \& Collins, B. E. (2002). Gender, relationship status, and stereotyping about sexual risk. Personality and Social Psychology Bulletin, 28, 1483-1494. doi:10.1177/014616702237576

Cross, S. E., Bacon, P. L., \& Morris, M. L. (2000). The relationalinterdependent self-construal and relationships. Journal of Personality and Social Psychology, 78, 791-808. doi:10.1037/0022-3514.78.4.791

Cross, S. E., \& Madson, L. (1997). Models of the self: Self-construal and gender. Psychological Bulletin, 122, 5-37. doi:10.1037/00332909.122.1.5

Cutright, K. M., Wu, E. C., Banfield, J. C., Kay, A. C., \& Fitzsimons, G. J. (2011). When your world must be defended: Consuming to justify the system. Journal of Consumer Research. Advance online publication. doi:10.1086/658469

Day, M. V., Yoshida, E., \& Kay, A. C. (2011). When the rich and poor are more or less human: Complementary forms of infrahumanization as a justification for inequality. Manuscript in preparation.

Deaux, K. (1985). Sex and gender. Annual Review of Psychology, 36, 49-81. doi:10.1146/annurev.ps.36.020185.000405

DePaulo, B. M. (2006). Singled out: How singles are stereotyped, stigmatized, and ignored, and still live happily ever after. New York, NY: St. Martin's Press.

DePaulo, B. M., \& Morris, W. L. (2005). Singles in society and in science. Psychological Inquiry, 16, 57-83. doi:10.1207/s15327965pli162\&3_01

DePaulo, B. M., \& Morris, W. L. (2006). The unrecognized stereotyping and discrimination against singles. Current Directions in Psychological Science, 15, 251-254. doi:10.1111/j.1467-8721.2006.00446.x

Eagly, A. H. (1987). Sex differences in social behaviour: A social role explanation. Hillsdale, $\mathrm{NJ}$ : Erlbaum.

Edwards, K., \& Smith, E. E. (1996). A disconfirmation bias in the evaluation of arguments. Journal of Personality and Social Psychology, 71, 5-24. doi:10.1037/0022-3514.71.1.5

Fein, S., \& Spencer, S. J. (1997). Prejudice as self-image maintenance: Affirming the self through derogating others. Journal of Personality and Social Psychology, 73, 31-44. doi:10.1037/0022-3514.73.1.31

Fiske, S. T., \& Taylor, S. E. (1991). Social cognition. New York, NY: McGraw-Hill

Gabriel, S., \& Gardner, W. L. (1999). Are there "his" and "hers" types of interdependence? The implications of gender differences in collective versus relational interdependence for affect, behavior, and cognition. Journal of Personality and Social Psychology, 77, 642-655. doi: 10.1037/0022-3514.77.3.642

Glick, P., \& Fiske, S. T. (1996). The Ambivalent Sexism Inventory: Differentiating hostile and benevolent sexism. Journal of Personality and Social Psychology, 70, 491-512. doi:10.1037/0022-3514.70.3.491

Glick, P., \& Fiske, S. T. (2001). Hostile and benevolent sexism as complementary justifications for gender inequality. American Psychologist, 56, 109-118. doi:10.1037/0003-066X.56.2.109

Greitemeyer, T. (2009). Stereotypes of singles: Are singles what we think? European Journal of Social Psychology, 39, 368-383. doi:10.1002/ ejsp.542

Guimond, S., Chatard, A., Martinot, D., Crisp, R. J., \& Redersdorff, S. (2006). Social comparison, self-stereotyping, and gender differences in self-construals. Journal of Personality and Social Psychology, 90, 221242. doi: $10.1037 / 0022-3514.90 .2 .221$

Hafer, C. L. (2000). Do innocent victims threaten the belief in a just world?
Evidence from a modified Stroop task. Journal of Personality and Social Psychology, 79, 165-173. doi:10.1037/0022-3514.79.2.165

Hahn, A., \& Cohen, G. L. (2008, June). From a "should" to an "is": An idealistic fallacy. Paper presented at the tri-annual meeting of the European Association of Experimental Social Psychology, Opatja, Croatia.

Hersch, J., \& Stratton, L. S. (2000). Household specialization and the marriage wage premium. Industrial and Labor Relations Review, 54, 78-94. doi:10.2307/2696033

Jackman, M. R. (1994). The velvet glove: Paternalism and conflict in gender, class, and race relations. Berkeley, CA: University of California Press.

Jost, J. T., \& Banaji, M. R. (1994). The role of stereotyping in systemjustification and the production of false consciousness. British Journal of Social Psychology, 33, 1-27.

Jost, J. T., Banaji, M. R., \& Nosek, B. A. (2004). A decade of system justification theory: Accumulated evidence of conscious and unconscious bolstering of the status quo. Political Psychology, 25, 881-919. doi:10.1111/j.1467-9221.2004.00402.x

Jost, J. T., \& Hunyady, O. (2003). The psychology of system justification and palliative function of ideology. European Review of Social Psychology, 13, 111-153. doi:10.1080/10463280240000046

Jost, J. T., \& Hunyady, O. (2005). Antecedents and consequences of system-justifying ideologies. Current Directions in Psychological Science, 14, 260-265. doi:10.1111/j.0963-7214.2005.00377.x

Jost, J. T., \& Kay, A. C. (2005). Exposure to benevolent sexism and complementary gender stereotypes: Consequences for specific and diffuse forms of system justification. Journal of Personality and Social Psychology, 88, 498-509. doi:10.1037/0022-3514.88.3.498

Jost, J. T., Kivetz, Y., Rubini, M., Guermandi, G., \& Mosso, C. (2005). System-justifying functions of complementary regional and ethnic stereotypes: Cross-national evidence. Social Justice Research, 18, 305333. doi: $10.1007 / \mathrm{s} 11211-005-6827-\mathrm{z}$

Jost, J. T., Ledgerwood, A., \& Hardin, C. D. (2008). Shared reality, system justification, and the relational basis of ideological beliefs. Social and Personality Psychology Compass, 2, 171-186. doi:10.1111/j.17519004.2007.00056.x

Jost, J. T., Pelham, B. W., \& Carvallo, M. R. (2002). Non-conscious forms of system justification: Implicit and behavioral preferences for higher status groups. Journal of Experimental Social Psychology, 38, 586-602. doi:10.1016/S0022-1031(02)00505-X

Kay, A. C., Gaucher, D., McGregor, I., \& Nash, K. (2010). Religious conviction as compensatory control. Personality and Social Psychology Review, 14, 37-48. doi:10.1177/1088868309353750

Kay, A. C., Gaucher, D., Napier, J. L., Callan, M. J., \& Laurin, K. (2008). God and the government: Testing a compensatory control mechanism for the support of external systems. Journal of Personality and Social Psychology, 95, 18-35. doi:10.1037/0022-3514.95.1.18

Kay, A. C., Gaucher, D., Peach, J. M., Laurin, K., Friesen, J., Zanna, M. P., \& Spencer, S. J. (2009). Inequality, discrimination, and the power of the status quo: Direct evidence for a motivation to see the way things are as the way they should be. Journal of Personality and Social Psychology, 97, 421-434. doi:10.1037/a0015997

Kay, A. C., \& Jost, J. T. (2003). Complementary justice: Effects of "poor but happy" and "poor but honest" stereotype exemplars on system justification and implicit activation of the justice motive. Journal of Personality and Social Psychology, 85, 823-837. doi:10.1037/00223514.85.5.823

Kay, A. C., Jost, J. T., \& Young, S. (2005). Victim derogation and victim enhancement as alternative routes to system justification. Psychological Science, 16, 240-246. doi:10.1111/j.0956-7976.2005.00810.x

Kay, A. C., Shepherd, S., Blatz, C. W., Chua, S. N., \& Galinksy, A. (2010), For God (or) country: The hydraulic relation between government instability and belief in religious sources of control. Journal of Personality and Social Psychology, 99, 725-739. doi:10.1037/a0021140 
Kelley, H. H. (1983). Love and commitment. In H. H. Kelley et al. (Eds.), Close relationships (pp. 265-314). New York, NY: Freeman.

Lau, G. P., Kay, A. C., \& Spencer, S. J. (2008). Loving those who justify inequality: The effects of system threat on attraction to women who embody benevolent sexist ideals. Psychological Science, 19, 20-21. doi:10.1111/j.1467-9280.2008.02040.x

Lerner, M. J. (1980). The belief in a just world: A fundamental delusion. New York, NY: Plenum Press.

Loh, E. S. (1996). Productivity differences and the marriage wage premium for White males. Journal of Human Resources, 31, 566-589. doi: $10.2307 / 146266$

Lord, C. G., Ross, L., \& Lepper, M. R. (1979). Biased assimilation and attitude polarization: The effects of prior theories on subsequently considered evidence. Journal of Personality and Social Psychology, 37, 2098-2109. doi:10.1037/0022-3514.37.11.2098

Major, B., Spencer, S., Schmader, T., Wolfe, C., \& Crocker, J. (1998). Coping with negative stereotypes about intellectual performance: The role of psychological disengagement. Personality and Social Psychology Bulletin, 24, 34-50. doi:10.1177/0146167298241003

Marigold, D. C., Holmes, J. G., \& Ross, M. (2007). More than words: Reframing compliments from romantic partners fosters security in low self-esteem individuals. Journal of Personality and Social Psychology, 92, 232-248. doi:10.1037/0022-3514.92.2.232

Mikulincer, M., \& Shaver, P. R. (2005). Attachment security, compassion, and altruism. Current Directions in Psychological Science, 14, 34-38. doi:10.1111/j.0963-7214.2005.00330.x

Miller, D. T., \& Ratner, R. K. (1998). The disparity between the actual and assumed power of self-interest. Journal of Personality and Social Psychology, 74, 53-62. doi:10.1037/0022-3514.74.1.53

Morris, W. L., DePaulo, B. M., Hertel, J., \& Taylor, L. C. (2008). Singlism - another problem that has no name: Prejudice, stereotypes, and discrimination against singles. In T. G. Morrison \& M. A. Morrison (Eds.), The psychology of modern prejudice (pp. 165-194). Hauppauge, NY: Nova Science.

Morris, W. L., Sinclair, S., \& DePaulo, B. M. (2007). No shelter for singles: The perceived legitimacy of marital status discrimination. Group Processes \& Intergroup Relations, 10, 457-470. doi:10.1177/ 1368430207081535

Murray, S. L., Holmes, J. G., \& Collins, N. L. (2006). Optimizing assurance: The risk regulation system in relationships. Psychological Bulletin, 132, 641-666. doi:10.1037/0033-2909.132.5.641

Murray, S. L., Holmes, J. G., \& Griffin, D. W. (2000). Self-esteem and the quest for felt security: How perceived regard regulates attachment processes. Journal of Personality and Social Psychology, 78, 478-498. doi:10.1037/0022-3514.78.3.478

Pillsworth, E. G., \& Haselton, M. G. (2005). The evolution of coupling. Psychological Inquiry, 16, 98-104.
Pomerantz, E. M., Chaiken, S., \& Tordesillas, R. S. (1995). Attitude strength and resistance processes. Journal of Personality and Social Psychology, 69, 408-419. doi:10.1037/0022-3514.69.3.408

Pratto, F., \& Walker, A. (2004). The bases of gendered power. In A. E. Beall, A. H. Eagly, \& R. J. Sternberg (Eds.), The psychology of gender (pp. 242-268). New York, NY: Guilford Press.

Preacher, K. J., Curran, P. J., \& Bauer, D. J. (2006). Computational tools for probing interaction effects in multiple linear regression, multilevel modeling, and latent curve analysis. Journal of Education and Behavioral Statistics, 31, 437-448. doi:10.3102/10769986031004437

Rudman, L. A., \& Glick, P. (1999). Feminized management and backlash toward agentic women: The hidden costs to women of a kinder, gentler image of middle managers. Journal of Personality and Social Psychology, 77, 1004-1010. doi:10.1037/0022-3514.77.5.1004

Sherman, D. K., \& Cohen, G. L. (2002). Accepting threatening information: Self-affirmation and the reduction of defensive biases. Current Directions in Psychological Science, 11, 119-123. doi:10.1111/14678721.00182

Sidanius, J., Levin, S., Liu, J., \& Pratto, F. (2000). Social dominance orientation, anti-egalitarianism, and the political psychology of gender: An extension and cross-cultural replication. European Journal of Social Psychology, 30, 41-67. doi:10.1002/(SICI) 1099-0992(200001/02)30:1<41:: AID-EJSP976>3.0.CO;2-O

Sidanius, J., \& Pratto, F. (1999). Social dominance: An intergroup theory of social hierarchy and oppression. New York, NY: Cambridge University Press.

Sidanius, J., Pratto, F., \& Bobo, L. (1994). Social dominance orientation and the political psychology of gender: A case of invariance? Journal of Personality and Social Psychology, 67, 998-1011. doi:10.1037/00223514.67.6.998

Steele, C. M., \& Liu, T. J. (1983). Dissonance processes as selfaffirmation. Journal of Personality and Social Psychology, 45, 5-19. doi:10.1037/0022-3514.45.1.5

United Nations Development Programme. (2000). Human development report 2000. New York, NY: Oxford University Press.

Wakslak, C. J., Jost, J. T., \& Bauer, P. (in press). Spreading rationalization: Increased support for large-scale and small-scale social systems following system threat. Social Cognition.

World Values Survey. (2006). European and World Values Surveys fourwave integrated data file, 1981-2004, v. 20060423 [Data file]. Retrieved from http://www.wvsevsdb.com/wvs/WVSData.jsp

Received March 2, 2010

Revision received January 24, 2011

Accepted January 31, 2011 